\title{
MORADORES DE RUA, QUEM SÃo ELES?Um Estudo Sobre a População de Rua Atendida pela Casa da Sopa "Capitão Vendramini” de Três Corações
}

\author{
Luiza Elena da $\operatorname{COSTA}^{1}$ \\ Vânia Maria de MESQUITA \\ Ana Paula CAMPOS ${ }^{3}$ \\ ${ }^{1}$ Graduanda em Serviço Social pela Universidade Vale do Rio Verde, luiza.bissau@ @otmail.com \\ ${ }^{2}$ Graduanda em Serviço Social pela Universidade Vale do Rio Verde, vaninhalisse@gmail.com \\ ${ }^{3}$ Professora Mestre do Curso de Serviço Social da Universidade Vale do Rio Verde, paulacampos.apc@gmail.com
}

Recebido em: 15/04/2015 - Aprovado em: 25/08/2015 - Disponibilizado em: 30/10/2015

\begin{abstract}
Resumo
O presente artigo é um resumo do estudo intitulado "Moradores de Rua, Quem São Eles? Um Estudo Sobre a População de Rua Atendida pela Casa da Sopa "Capitão Vendramini” de Três Corações. Neste pretendeu-se dar voz e vez àqueles que a sociedade insiste em tornar invisíveis. Tivemos como matéria prima, o vivido humano, desses que são excluídos da comunidade, sendo assim, impedidos de acessar seus direitos sociais e exercer sua cidadania de fato e de direito. Esse encontro de acadêmicos e a população em situação de rua, possibilitou uma transformação substancial nos sujeitos envolvidos na pesquisa; aumentando nossa capacidade de olhar com mais criticidade a nossa realidade e a pensar em propostas que realmente minimizem às refrações da questão social na cidade de Três Corações; e trabalhamos com o pressuposto de que os instrumentos e instrumentais pertinentes ao Serviço Social se configuram num viabilizador para que essa parcela da população possa acessar seus direitos sociais. Ao entrarmos em contato com essa realidade levantamos algumas hipóteses e suposições, sobre os principais e reais motivos que levaram essas pessoas a viverem nas ruas; e se a Casa da Sopa Capitão Vendramini atende realmente às necessidades e direitos desse público em questão; ou se numa ação conjunta com o poder público municipal essa situação poderia ser modificada, levando-se em conta o amparo legal que esse segmento populacional possui, em se tratando da Constituição Federal de 1988, da Política Nacional de Assistência Social (PNAS) e Sistema Único de Assistência Social (SUAS).
\end{abstract}

Palavras chave: Serviço Social, Pessoa em Situação de Rua, Casa da Sopa "Capitão Vendramini", Três Corações.

\section{STREET RESIDENTS, WHO ARE THEY? A Study of the Attended Homelessness at Casa da Sopa "Capitão Vendramini" in Três Corações}

\begin{abstract}
This article is a summary of the study entitled "Homelessness, Who Are They? A Study of the attended homelessness at casa da Sopa "Capitão Vendramini" in Três Corações. This was intended to give voice and time to those that society insists become invisible. We had as raw material, the human lived, those who are excluded from the community, so prevented from accessing their social rights and exercise their citizenship fact and law. This meeting of academics and the people on the streets, made it possible to transform the subjects involved in research; increasing our ability to look more critical to our reality and thinking about proposals that really minimize the refractions of the social question in the city of Three Hearts; and work with the assumption that the tools and instruments relevant to social work to configure an enabler for this population can access their social rights. As we enter into contact with this reality raise some hypotheses and assumptions, on the main and real reasons that led these people to live on the streets; and the House of soup Captain Vendramini really meets the needs and rights of the public concerned; or in a joint action with the municipal authorities this situation could be modified, taking into account the legal support that this population segment has, in the case of the Federal Constitution of 1988, the National Social Assistance Policy (PNAS) and System Unified Social Services (SUAS).
\end{abstract}

Keywords: Social Work, Person in Homeless, Casa da Sopa "Capitão Vendramini", Três Corações. 


\section{INTRODUÇÃ̃O}

O presente estudo cujo tema é: "Moradores de Rua, Quem São Eles? Um Estudo Sobre a População de Rua Atendida pela Casa da Sopa "Capitão Vendramini" de Três Corações, versa dobre o Serviço Social, enquanto profissão, e tem como matéria prima de trabalho a questão social que se expressa ou se manifesta em situações de exclusão, desigualdade social, descumprimento de direitos sociais e, principalmente, desrespeito aos Direitos Humanos.

A questão sobre moradores de rua é vivenciada nas mais variadas localidades e o que nos chama atenção, é a invisibilidade desses sujeitos devido a sua condição.

A sociedade não busca enfrentar essa condição e apenas alguns segmentos realizam trabalhos assistenciais ofertando alimentos e doações de roupas e cobertores em situações climáticas mais intensas, como o trabalho desenvolvido pela Casa da Sopa Capitão Vendramini.

No cotidiano das cidades podemos observar pessoas que vivem nas ruas, ou que passam o dia nela, seja perambulando ou à procura de trabalho. No entanto, nos questionamos enquanto futuros assistentes sociais, qual seriam os motivos que levam o indivíduo a escolher a vivência nas ruas? E qual a situação em que se encontram? Existe possibilidade de restaurar sua convivência e vínculo familiar? Essas e muitas outras questões norteiam a presente pesquisa, uma vez que buscamos "dar voz às ruas", através dos seus moradores.

No município de Três Corações a realidade não é diferente de grandes e médias cidades, pois existe uma população em situação de rua. Mas devido à proximidade com a cidade de São Tomé das Letras, muitos migrantes passam pelas ruas tricordianas e buscam formas de se encaminhar e permanecer na região.

Outros fatores que também contribuem para a condição de rua são os rompimentos dos vínculos familiares por questões de uso e abuso de álcool e drogas, no entanto, não se pode generalizar essas causas sem que se faça uma leitura da realidade buscando essas informações junto a população em situação de rua de Três Corações.

Devido à dificuldade de localização constante dessa população, bem como, o conhecimento sobre o trabalho desempenhado pela Casa da Sopa "Capitão Vendramini” no amparo à população, e dentre esse público, os moradores de rua. Relacionamos a pesquisa a essa tradicional instituição tricordiana que nos seus mais de 50 anos presta acolhimento aos menos favorecidos da sociedade.

Também utilizamos documentos e legislações atualizadas sobre a questão da população de rua visando contribuir teoricamente para o enfrentamento e atendimento dessa demanda social, haja vista que na contemporaneidade não se pode 
conceber a existência de uma cidadania apenas de papel.

\section{HISTÓRIA DO SERVIÇO SOCIAL}

Serviço Social, o próprio nome exterioriza a essência da profissão que se insere nas relações sociais, enquanto geradoras de conflitos entre classes, e desses advém o objeto de trabalho do Assistente Social, a questão social.

Portanto, não há como falar de Serviço Social sem mencionar as relações sociais e o modelo de produção capitalista, pois estes se configuram em fatores determinantes na história das sociedades, e denotam a necessidade de um profissional técnico capaz não só de compreender, mas também de decifrar a realidade que está posta, objetivando a minimização das manifestações multifacetadas da questão social.

No entanto, não é possível falar em Serviço Social, sem mencionar uma pessoa que é considerada por muitos autores como a precursora dessa profissão, Mary Elly Richmond, nascida em Belleville, Illinois no ano de 1861; perdeu os pais enquanto jovem, e foi viver com sua avó, que era sufragista das mulheres.

Devido a essa convivência, desenvolveu um senso crítico, em relação aos pauperizados da época. Graduou-se pela High School com apenas dezesseis anos de idade; mudou-se para Nova Iorque, onde viveu na pobreza por dois anos. Voltou a viver em Baltimore, e se candidatou a Tesoureiro Assistente com a Charity Organization Society (COS), e esta foi a primeira organização que desenvolveu trabalhos com os pobres, deficientes e necessitados de maneira estruturada; e esse foi seu contributo inicial com o Serviço Social. Os modelos de atendimento eram conhecidos como: serviço social de caso, grupo e de comunidade.

Segundo Marx em seu livro, O Capital, são os produtos privados em forma de valor que determinam a relação social; o dinheiro regula a troca, e o trabalho é tido como forma de capital. Diante desta premissa vimos à importância de discorrermos sobre as relações sociais e o mundo do trabalho.

Segundo Iamamoto e Carvalho (2009),

O processo capitalista de produção expressa, portanto uma maneira historicamente determinada de os homens produzirem e reproduzirem as condições materiais da existência humana e as relações sociais através das quais levam a efeito a produção (IAMAMOTO e CARVALHO, 2009, p.30).

É no modo de produção capitalista que as relações sociais se manifestam, haja vista, que as duas estão intrinsecamente ligadas.

Conforme Iamamoto e Carvalho (2009),

As relações sociais aparecem, pois, mistificadamente, como relações entre coisas, esvaziadas de sua historicidade. A reificação do capital é, pois, a forma mistificada em que a relação social do capital aparece na superfície da sociedade 
(IAMAMOTO e CARVALHO, 2009, p.31).

Raichellis (2006), também entende que o início do Serviço Social no Brasil tem estreita ligação com o evento da urbanização decorrente da industrialização.

As origens do Serviço Social devem ser localizadas na emergente sociedade urbano industrial dos anos 30 do século $\mathrm{XX}$, em uma conjuntura peculiar do desenvolvimento capitalista, marcada por conflitos de classe, pelo crescimento numérico e qualitativo da classe operária urbana e pelas lutas sociais que esta desencadeia contra a exploração do trabalho e pela defesa dos direitos de cidadania (RAICHELLIS, 2006, p.§).

Na década de 30, com o advento da Revolução Industrial, as relações entre burguesia e proletariado ficaram ainda mais conturbadas, pois estes últimos estavam se organizando em associações e movimentos sociais e requerendo condições dignas de trabalho e moradia; e neste contexto conflituoso, surge o Estado como provedor da ordem, numa ação conjunta com a burguesia e a Igreja Católica.

Os proletários viviam em condições sub-humanas nas periferias dos grandes centros urbanos. Nas fábricas eram submetidos a jornadas exaustivas, sendo que o trabalho feminino e infantil beirava a escravidão.

Neste contexto, de forma embrionária surge o Serviço Social; mas atrelado aos moldes impostos pela Igreja Católica, de benesse e assistencialismo, ancorados em ações conservadoras, em que o indivíduo era considerado o único culpado por sua condição social, num viés de desresponsabilização do Estado.

Os profissionais eram tarefeiros a serviço do Estado; realizavam ações sanitaristas e de enquadramento da população aos moldes do capitalismo voraz; que se mantinha com a acumulação de bens, fetichismo mercadológico e exclusão social.

Após o fim da Primeira Guerra surgem algumas instituições sob a égide da Igreja Católica, sendo suas ações voltadas para a caridade; a benesse propriamente dita.

Em 1920, surge no Rio de Janeiro a Associação das Senhoras Brasileiras e em 1923 a Liga das Senhoras Católicas, em São Paulo, sendo que as duas instituições estavam ligadas à importantes famílias pertencentes a burguesia paulista e carioca. A Sra. Estella Faro, é considerada a precursora do Serviço Social no Rio de Janeiro.

No ano de 1922 é fundada a Confederação Católica precursora da Ação Católica, e a Sra. Estella Faro foi sua coordenadora, primando pelo apostolado laico.

Em 1932 ocorre a expansão da Ação Social e com ela a criação das primeiras escolas de Serviço Social.

O Movimento Laico foi um divisor de águas para a profissão segundo Iamamoto e Carvalho (2009), 
Será, no entanto, a partir do Movimento Laico que essas iniciativas embrionárias se multiplicarão, compreendidas dentro da Ação Católica. Tomarão aí sua forma de característica de apostolado social (IAMAMOTO

CARVALHO, 2009, p.167)

Surgiram algumas instituições com a finalidade de organizar a juventude católica para a ação social, dentre elas a Juventude Operária Católica (JOC).

Em 1932 surge o Centro de Estudos e Ação Social (CEAS), sob o controle da hierarquia, condensando a Ação Católica e a Ação Social.

Oficialmente falando o início do Serviço Social se deu com o Curso Intensivo de Formação Social para Moças, promovido pelas cônegas de Santo Agostinho e teve como convidada a Sra. Mlle. Adèle Loneaux da escola católica de Bruxelas. (IAMAMOTO e CARVALHO, 2009).

Mas no período da Ditadura Militar, a discussão sobre o Serviço Social sofreu uma estagnação, pois o Estado criou alguns benefícios previdenciários que eram voltados aos seus próprios interesses. Os Centros Sociais Urbanos e Rurais, Fundação Nacional do Bem-Estar do Menor (FUNABEM), e a Legião Brasileira de Assistência (LBA); realizavam ações paternalistas; sendo que, as organizações da sociedade civil é que realizavam ações voltadas para a população cada vez mais empobrecida pela ineficiência das políticas públicas focalistas e inexpressivas no que se referia a direitos sociais.

Houve um crescente na urbanização e por consequência um avultamento da pobreza em todo país, mas de forma mais expressiva nos grandes centros urbanos; direcionando as ações profissionais para alguns segmentos da sociedade, em detrimento da grande maioria da população extremamente pauperizada; neste ínterim são criadas as primeiras secretarias estaduais e municipais com a finalidade de dar respostas às novas demandas que emergiam da questão social.

As ações profissionais estavam atreladas aos moldes católicos, de benesse e caridade; sendo que suas intervenções explicitavam um moralismo religioso; objetivando o enquadramento das pessoas.

Mas no interior da profissão, havia uma inquietude que perpassava a luta pela consolidação dos direitos sociais, a distribuição equânime dos bens e produtos produzidos socialmente e a implementação de políticas públicas reguladas pelo Estado que realmente atendessem às necessidades dos proletários.

No entanto, apesar de estar inscrita na divisão sócio-técnica do trabalho, inicialmente sua atuação profisssional era de cunho regulador e focalista, em que a ordem social era o objetivo final, culminando com a propagação da hegemonia capitalista; mas esse fato não impediu que no âmago da 
profissão surgisse uma ânsia crescente por mudanças em seus paradigmas.

Surge então, o Movimento de Reconceituação, tencionando romper com os moldes tradicionalistas e conservadores; mas essa mudança não ocorreu de forma linear e uniforme. Segundo Faleiros:

Esse movimento reflete as contradições e confrontos das lutas sociais onde embatem tendências de conciliação e de reforma com outras de transformação da ordem vigente no bojo do processo revolucionário e ainda com outras que visam apenas modernizar e minimizar a dominação (FALEIROS, 1987, p.51).

As ações profissionais estavam atreladas aos moldes católicos, de benesse e caridade; sendo que suas intervenções explicitavam um moralismo religioso; objetivando o enquadramento das pessoas.

Mas no interior da profissão, havia uma inquietude que perpassava a luta pela consolidação dos direitos sociais, a distribuição equânime dos bens e produtos produzidos socialmente e a implementação de políticas públicas reguladas pelo Estado que realmente atendessem às necessidades dos proletários.

No entanto, apesar de estar inscrita na divisão sócio-técnica do trabalho, inicialmente sua atuação profissional era de cunho regulador e focalista, em que a ordem social era o objetivo final, culminando com a propagação da hegemonia capitalista; mas esse fato não impediu que no âmago da

profissão surgisse uma ânsia crescente por mudanças em seus paradigmas.

O Movimento de Reconceituação propõe um repensar na profissão, no que tange ao conhecimento teórico-metodológico; mas há uma divergência de opiniões entre autores do Serviço Social a respeito desse movimento, alguns consideram o movimento como algo temporal, restrito ao período que se iniciou; outros consideram que o mesmo ultrapassou as barreiras do tempo e está presente até os dias atuais.

Os profissionais procuravam uma nova identidade, a partir da análise, da realidade latino americana, que possuía suas peculiaridades, não podendo, portanto, seguir moldes do Serviço Social Franco-belga e Norte-americano; um dos diferenciais era o regime político vigente no Brasil, a Ditadura, período em as refrações da questão social ficaram mais evidentes, pois as ações do governo eram pautadas no desenvolvimentismo, sem que para isso fossem proporcionado a valorização dos trabalhadores enquanto cidadãos de direito.

Nesse momento da história o Serviço social tende a se aproximar dos movimentos sociais e a ter os primeiros contatos com as teorias marxianas, embora de maneira rudimentar. 


\section{AS POLÍticas PÚBLICAS E A POPULAÇÃO DE RUA}

Assim como a questão social da pobreza nos início do século XX era um caso de polícia. O fenômeno da situação de rua, sempre foi encarado como um desajuste do sujeito morador de rua e, portanto, uma questão de transgressão a ordem e aos bons costumes, passível de punição.

No Brasil de 1830com o Código Criminal do Império à 1890 com o Código Penal da República, não se observou mudanças significativas no que tange as pessoas em situação de rua. Somente em 1988, com a Constituição Federal; conhecida como Constituição Cidadã, é que os direitos dessas pessoas são reconhecidos e legalizados.

A Política de Assistência Social é reconhecida como tal a partir da Constituição Federal de 1988, que traz em seu texto, artigo 194 a regulamentação do tripé da Seguridade Social:

Art. 194. A seguridade social compreende um conjunto integrado de ações de iniciativa dos Poderes Públicos e da sociedade, destinadas a assegurar os direitos relativos à saúde, à previdência e à assistência social. (BRASIL, 2003, p.193).

Nos artigos 203 e 204 da Constituição Federal de 1988, a Assistência Social é regulamentada enquanto um direito social.

No ano de 2004 a Política Nacional de Assistência Social (PNAS) assegura cobertura a população em situação de rua. A especificação desse atendimento a esse público socialmente vulnerável está em concordância com a nossa Constituição Cidadã, pois traz em seu texto a igualdade de direitos perante a lei

A LOAS/1993, atualmente traz em seu artigo 23 a afirmação de direitos da população de rua:

$\mathrm{Na}$ organização dos serviços,da Assistência Social serão criados,programas de amparo; II - às pessoas que vivem em situação de rua". Estabelece a obrigatoriedade de criação de programas direcionados à população em situação de rua, no âmbito da organização dos serviços de assistência social, numa perspectiva de ação intersetorial (Redação dada pela Lei $\mathrm{n}^{\circ} 11.258$, de 2005) (BRASIL, 2008, p.§).

A Portaria $n^{\mathbf{o}}$ 381, do MDS, estabelece o Cofinanciamento de Serviços Continuados de Acolhimento para à População em Situação de Rua, em municípios com mais de 250 mil habitantes.

Com a aprovação do Conselho Nacional de Assistência Social (CNAS), o Decreto $n^{\circ} 7.053$ de 23 de dezembro de 2009 instituiu a Política Nacional para a População em Situação de Rua no Cadastro Único para Programas Sociais do Governo Federal.

Essa medida foi de extrema relevância, pois, no Brasil, a maioria das pessoas em situação de rua, não possuem amparo dos programas governamentais, e nem mesmo possuem documentos pessoais; o que as impede de exercer um dos direitos elementares de cidadania, dentre eles, o voto. 
$\mathrm{O}$ atendimento a essa população que utiliza a rua como espaço de moradia e/ou sobrevivência, foi tipificado pelo, SUAS, através da Resolução no 109 , de novembro de 2009, e publicada no Diário Oficial da União (DOU) em 25 de novembro do mesmo ano; e preconiza o atendimento a esse público em vários serviços tipificados dependendo da demanda ou violação dos direitos, e sua finalidade é desenvolver atividades direcionadas a promover a sociabilidade desses sujeitos, promovendo assim o fortalecimento e/ou restabelecimento dos vínculos familiares.

Para que a inclusão dessa parcela significativa da população seja realmente efetiva, se faz necessário a atuação de profissionais do Serviço Especializado em Abordagem Social, Serviço Especializado para Pessoas em situação de Rua, Serviço de Acolhimento, unidades e outros serviços da equipe PSE do SUAS municipal objetivando a identificação e encaminhamento para os postos de cadastramento. Mas caso haja uma recusa por parte da pessoa em procurar o serviço; mas manifeste interesse em fazer o cadastro, excepcionalmente, os profissionais responsáveis pela abordagem social poderão realizá-lo na rua; sem deixar de explicitar a importância dos postos de cadastramento.

Segundo Pereira (2006), houve uma transformação mais pontual nos programas sociais a partir da década de 90, com a regulamentação das legislações sociais e o início da organização da Assistência Social, percebe-se que a luta pela garantia desses direitos fica mais evidente.

\section{BREVE CONTEXTUALIZAÇÃO DE TRÊS CORAÇÕES}

O município de Três Corações se localiza na região Sul do Estado de Minas Gerais. Conhecida pela Terra do Pelé, a cidade é reconhecida nacionalmente por abrigar a EsSA (Escola de Sargentos das Armas) do Exército Brasileiro, bem como, por ser a cidade onde fica a Universidade Vale do Rio Verde (UninCor). A importância da UninCor está no fato de ser uma universidade comunitária, bem como ser uma instituição de ensino superior que abriga cursos superiores e programas de pósgraduação de reconhecimento pela principais agências de pesquisa nacional.

O município comporta uma política de desenvolvimento industrial oferecendo inúmeras oportunidades de investimentos, pois além de dispor de um Distrito Industrial, localizado às margens da Rodovia Fernão Dias (BR-381), também oferece mão de obra qualificada pela estrutura educacional disponível para a população (SENAI, SENAC, IF Sul de Minas, UNINCOR, etc.). A área do distrito industrial é de aproximadamente $2.634 .944,47 \mathrm{~m}^{2}$, sendo que no setor industrial destacam-se as indústrias de produtos derivados do leite (leite em pó, manteiga, queijo), metalúrgicos (esquadria 
metálicas, botijão de gás, rodas de aço para automóveis, fios de cobre) fabricas de ração, fertilizantes, couro, calçados, brinquedos de plásticos entre outros.

\section{A PRESTAÇÃO DE ASSISTÊNCIA SOCIAL AO MORADOR DE RUA EM TRÊS CORAÇÕES}

Não há um perfil definido para as pessoas em situação de rua em Três Corações, tendo em vista, que são jovens, idosos, mulheres, homens e homossexuais. Eles ficam em situação de mendicância pelas ruas da cidade.

A higiene pessoal e uma refeição diária são feitas por alguns no SOS (Serviços e Obras Sociais) que é subordinado à Secretaria Municipal de Desenvolvimento Social; mas em sua maioria no que se refere à alimentação, vestuário e acolhimento, eles procuram a Casa da Sopa Capitão Vendramini, que é uma instituição filantrópica que segue a doutrina espírita.

Em Três Corações, as pessoas em situação de rua são atendidas na Casa da Sopa, que é um Órgão Assistencial do Núcleo da Cruzada dos Militares Espíritas de Três Corações, embora sua data de fundação seja de 02/09/1966, o Capitão Vendramini distribuiu por seis anos e meio a sopa em sua residência, à rua Getúlio Vargas n 492 - TC - MG, tendo iniciado esta atividade em 02 de janeiro de 1960.
O Albergue Noturno foi inaugurado em 11 de abril de 1966, no endereço atual do Núcleo da Cruzada e encerrou suas atividades em 13 de dezembro de 2003.

Diante desse fato percebe-se a falta de amparo do Estado como responsável legal pelo bem estar da sociedade e a tendência crescente de transferência da responsabilidade pelo acolhimento das demandas sociais dos extremamente excluídos pelo sistema econômico sobre os ombros de instituições de cunho religioso.

A grande dificuldade nessa transferência, está no fato de que, as mesmas não primam pela emancipação dos sujeitos e nem mesmo pela garantia de seus direitos sociais, haja vista, que não possuem profissionais qualificados para decifrar essa complexa realidade de uma parcela da sociedade, que a mesma insiste em tornar invisível pensando ser possível negar direitos constitucionais.

\section{ANÁLISE DE DADOS}

A maioria das pessoas em situação de rua são homens que abandonam suas famílias e sobrevivem nas ruas de Três Corações, correspondendo à $89 \%$ do sexo masculino e $11 \%$ do feminino. Sendo que a maioria dos entrevistados possuem relação estável com parceiros mesmo morando nas ruas. Conforme as informações sobre o estado civil coletadas podemos verificar que a maioria dos 
moradores de rua são homens que foram casados e que abandonaram as famílias originais por questões diversas mas que constituíram nas ruas novas relações com outras companheiras.

Outra informação relevante esta na questão profissional, uma vez que os entrevistados exerciam atividades profissionais antes de ir para as ruas. As atividades mais citadas foram Pedreiro ou trabalhador rural que correspondeu a metade das afirmações, seguida por Marceneiro, Mecânico e Cabeleireira/Diarista. Analisando o conjunto de profissões ou habilidades nos faz refletir que esses moradores de rua tem potencial para ser inseridos novamente e em condições dignas no mercado de trabalho. No entanto conforme o próprio relato desses, a questão da rua e a falta de um local de referência para cuidarem da higiene pessoal, utilizar como base para correspondência, local em condições sanitárias e adequadas para permanecerem até estejam independentes com o controle da vida autônomos é uma grande queixa dos moradores de rua e claro, uma falha do poder público local.

O uso de álcool e droga que foi confirmado por todos os entrevistados. Vemos inicialmente que os mesmos não consideram isso como um agravo de saúde. Também temos uma questão dupla sobre esses números, na abordagem os moradores de rua foram questionados se tem ou tiveram problema com álcool e/ou drogas. $\mathrm{Na}$ resposta, boa parte declarou ser o motivo da saída de casa para as ruas, não especificando se essa situação de dependência do álcool ou drogas ainda estava acontecendo.

Acredita-se que pelas condições precárias de sobrevivência de grande parte das pessoas em situação de rua, que o uso de substâncias entorpecentes seja uma realidade para a maioria dar conta de sobreviver ao cotidiano degradante das ruas.

Em relação às doações e aos auxílios recebidos, vemos uma situação diferente, os moradores confirmaram receber alimentos, roupas e medicamentos mas não relataram receber doações em dinheiro. Essa observação é interessante quando se avalia que existe um mito sobre a questão de que as pessoas que doam dinheiro para os moradores de rua contribuem para a perpetuação da mendicância. Mas conforme é observado nas falas dos moradores e nos números dos gráficos o contexto familiar é mais decisivo para que esses permaneçam nas ruas.

Tive problemas com meu irmão, estive preso e quando voltei ele brigou comigo. Minha irmã tentou me levar prá casa... [...] É triste não poder viver com a família... depender da ajuda dos outros prá tudo. (Morador de Rua 07).

Morava com uma mulher... doze anos e me separei... morei com outra e tive problemas... depois... fui morar na rua. (Morador de Rua 05).

Fui prá rua por causa de discussão com familiares... [...] Passo sufoco, passo necessidade, tenho 
que pedir... passo vergonha... [...] Acho que as pessoas que moram na rua se acostumam e não querem voltar. (Moradora de Rua 08)

Ao aferirmos quais seriam os serviços ou instituições que atendem a população de rua de Três Corações obtivemos as seguintes informações : A maioria (60\%) receberam auxílio da Casa da Sopa, seguida pelo auxílio da Assistência social com a participação menor (13\%), foram citados os serviços de saúde pública (06\%), a igreja $(07 \%)$ e o Comércio Local (07\%). No entanto, fica nítido pelas informações que a Casa da Sopa é principalmente instituição que acolhe a demanda das pessoas em situação de rua de Três Corações.

Se não fosse a Casa da Sopa não teria o que comer.

(Morador de Rua 07)

Dentre os auxílios prestados pela Casa da Sopa aos moradores de rua estão na Preparação e distribuição de Alimentação (23\%), trabalho na Rouparia com distribuição gratuita e administração do brechó/bazar per manete $(23 \%)$, o serviço de Farmácia com distribuição de medicamentos (23\%), a realização de Orientações Espirituais e Sociais $(16 \%)$ e o fornecimento de passagens de ônibus (15\%), quando solicitados.

\section{CONSIDERAÇÕES FINAIS}

No decorrer desses meses de pesquisa bibliográfica e trabalho de campo, surgiram diversas situações que nos levaram a pensar e repensar conceitos e preconceitos de nossa sociedade em relação à população de rua tricordiana.

Uma vez que a maioria dos entrevistados (moradores de rua) disse gostar e querer morar nas ruas da cidade de Três Corações. Demonstram ter consciência das causas de sua saída para as ruas, dentre elas o uso/abuso de drogas lícitas e ilícitas, o rompimento com os familiares, que não aceitaram o seu modo de vida e a sensação de liberdade experimentada nas ruas.

A compreensão da realidade é um desafio posto ao assistente social na contemporaneidade, segundo Iamamoto (2004), e esse fato denota quão importante foi a escolha do método quanti qualitativo da pesquisa, pois oportunizou o descortinar da realidade social das pessoas em situação de rua em Três Corações, incorrendo para uma investigação com um olhar holístico quanto às possibilidades para a emancipação dos sujeitos sociais e a efetivação da cidadania.

O profissional assistente social possui competência teórico-metodológica, técnicaoperativa e ético-política para propor e operacionalizar ações que viabilizem a intersetorialidade das políticas em conformidade com a Política Nacional de Assistência Social (PNAS), e assim lutar pela implementação de projetos que oportunizem o acesso das pessoas em situação de rua aos 
equipamentos sociais, conforme preconiza nossa Carta Magna.

Após realizarmos esse estudo compreendemos que as ações a serem executadas devem primar pelo acesso desses sujeitos ao trabalho remunerado e um albergue noturno, para que não percam a noção de pertencimento, que é um determinante para a vida em sociedade, objetivando o preenchimento das necessidades básicas desse público.

Constatamos que a população de rua em Três Corações é constituída em 89\% (oitenta e nove por cento) por homens, e estes possuem profissões das mais diversas. Ao serem perguntados sobre a inserção no mercado de trabalho, alguns argumentaram que não possuíam casa, e nem mesmo roupas e tão pouco documentos para procurarem um emprego de qualquer natureza.

Concluímos com essa pesquisa, que os moradores de rua, de Três Corações, atendidos na Casa da Sopa Capitão Vendramini, desconhecem seus direitos, enquanto cidadãos, e são reféns do sistema econômico que os mantém reféns do sistema econômico que os mantém alienados e vitimizados por sua condição social e econômica.

Em relação aos voluntários da Casa da Sopa, percebemos que a maioria não conhece o trabalho do assistente social com profundidade. Uma vez que se referem ao mesmo como um benfeitor dos necessitados, indicando a similaridade entre as ações realizadas pela instituição e a profissão.

Acreditamos que este estudo sinalizou as possibilidades de realização de um trabalho intersetorial pautado no envolvimento dos governos municipais, estaduais, federais, sociedade civil e Organizações não Governamentais pode viabilizar direitos sociais e efetivar a verdadeira cidadania. Que o nosso país, apesar das dimensões continentais e das desigualdades na mesma proporção, deve ter um pacto pela justiça social e a igualdade entre todos.

Alguns questionamentos levantados foram satisfatoriamente respondidos, no que tange às motivações que levaram os indivíduos a viverem em situação de rua, e constatamos que essa realidade tem como causa, uma gama de conjunturas.

Dentre elas, podemos citar: a miséria dos sujeitos, o descaso do poder público, quando se eximem de suas responsabilidades não proporcionando serviços adequados como um albergue noturno e condições de reingresso no mercado de trabalho; e ausência de uma ação mais efetiva do CREAS, pautada no restabelecimento e fortalecimento dos vínculos familiares.

A falta de instrumentais e estruturas adequadas para a intervenção do assistente social, demonstra uma fragilidade do poder público no enfrentamento da questão que permeia a situação de rua. 
Podemos inferir que essas condições desmotivam o profissional do Serviço Social à elaborar estratégias que contemplem o usuário em sua integralidade, impossibilitando assim, ações que incorram na criação de emprego e renda, objetivando o atendimento qualificado dessas demandas em específico.

\section{REFERÊNCIAS}

BRASIL, Republica Federativa do. BRASIL,Republica Federativa do. Constituição Federal de 1988. Brasília: Senado Federal, 2014. Disponível em:http://www.senado.gov.br/legislacao/const /con1988/con1988_05.10.1988/con1988.pdf Acessado em: 17/11/2014 às 11h56min.

BRASIL, Republica Federativa do. Política Nacional para a População em Situação de Rua. Brasília: Governo Federal, 2008. Disponível em: http://www.recife.pe.gov.br/noticias/arquivos/ 2297.pdf Acessado em: 19/11/2014 às 08h51min.

CASTEL, Robert. Desigualdade e a Questão Social. São Paulo: Educ., 1997.

FALEIROS, V. P. Confrontos teóricos do movimento de reconceituação do Serviço Social na América Latina. In: Revista Serviço Social e Sociedade, São Paulo: Cortez Ano VII, no 24 - p. 49-69, Agosto/1987

IAMAMOTO, Marilda Vilela; CARVALHO, Raul de, Relações Sociais e Serviço Social no Brasil: esboço de uma interpretação histórico-metodológica. $27^{\mathrm{a}}$ ed. São Paulo: Cortez /CELATS, 2009.

RAICHELIS, Raquel. O Serviço Social no Brasil. In: CFESS, Conselho Federal de Serviço Social. Agenda CFESS 2006. Brasília: CFESS, 2006.
VENDRAMINI, Casa da Sopa Capitão. In: Site Institucional Disponível em: http://www.casadasopacapitaovendramini.co m/Acessado em: 01/09/2014 às 20:12. 